\title{
Methodology of Improving the Professional Activity of the Future Teacher of Technology on the Basis of Modern Educational Technologies
}

\author{
Siddik Kakhkhorov ${ }^{1}$, Zilola Rasulova ${ }^{2, *}$ \\ ${ }^{1}$ Department of Physics, Faculty of Physics and Mathematics, Bukhara State University, Bukhara, 200100, Uzbekistan \\ ${ }^{2}$ Department of Pedagogy, Faculty of Pedagogy, Bukhara State University, Bukhara, 200100, Uzbekistan
}

Received June 30, 2020; Revised October 3, 2020; Accepted November 1, 2020

\section{Cite This Paper in the following Citation Styles}

(a): [1] Siddik Kakhkhorov, Zilola Rasulova, "Methodology of Improving the Professional Activity of the Future Teacher of Technology on the Basis of Modern Educational Technologies, "Universal Journal of Educational Research, Vol. 8, No. 12, pp. 7006 - 7014, 2020. DOI: 10.13189/ujer.2020.081268.

(b): Siddik Kakhkhorov, Zilola Rasulova (2020). Methodology of Improving the Professional Activity of the Future Teacher of Technology on the Basis of Modern Educational Technologies. Universal Journal of Educational Research, 8(12), 7006 - 7014. DOI: 10.13189/ujer.2020.081268.

Copyright $\bigcirc 2020$ by authors, all rights reserved. Authors agree that this article remains permanently open access under the terms of the Creative Commons Attribution License 4.0 International License

\begin{abstract}
The following article deals with the role of modern pedagogical technologies in the educational process, the creation of innovative activities of future teachers of Technology on the basis of pedagogical technologies, and the ways to increase creativity as well. Definitions of foreign and domestic scientists on pedagogical technologies are comparatively analyzed in the research work. The main purpose of the research is completely to get rid of the learning process from a homogeneous system, to provide the process with technology, that is, to design lessons on the basis of modern technologies, to predict the expected outcome, to increase time productivity, to determine the level of knowledge, skills and abilities. The main task of research work is to train future teachers of Technology education using modern information technologies and their experience in the educational process, to improve their professional skills constantly, to master effective innovative methods and put them into practice. Based on the advanced technology education model, it is planned to develop students' creative skills by organizing new pedagogical games, using visual methods to explain practical topics, creating problem situations, organizing discussions, sharing students' ideas, developing creative activity, forming independent thinking. The main novelty of the research is the pedagogical technology of teaching processes, organized in two traditional and non-traditional
\end{abstract}

forms, and experimental work. The results of experimental work were analyzed using mathematical-statistical methods, which is one of the research methods of pedagogy. As a result, it has been proved on the basis of statistical analysis that the efficiency of students' mastering of the course has increased.

Keywords Pedagogical Technology, Modern Educational Technologies, Teaching Methods, Creativity, Innovative Approaches

\section{Introduction}

The goal of accelerating the education of the population and increasing its effectiveness in order to get place of our country among the developed countries also requires the use of advanced educational technologies. Therefore, the most important strategic directions in education are the innovative activities of educational institutions. This is one of the key issues of modern technology in all educational areas, especially in the field of technology training in higher education institutions that produce highly qualified specialists.

The main tasks are: modernization of educational process in higher educational institutions of the Republic, 
development of professional competence of teachers in improving the quality of the system of training of teachers, equipping them with modern professional knowledge, skills and abilities in the field, independent use of scientific and technical innovations and solution of perspective tasks. One of the most important task is developing skills, at the same time ensuring the interrelationship, continuity and of the stages of education; implementation of advanced educational technologies in the organization of educational process in higher education, ensuring the quality of educational and methodical complexes, constant improvement of computer skills and use of the Internet by future professors in the implementation of pedagogical technologies; further of development of higher education with information resources and modern educational literature; the study of the best international practices in these areas determines the structure activities of higher educational institutions, in particular, pedagogical staff [1].

Nowadays, one of the requirements of the "National Training Program" is to accelerate the training of students in the educational process using new pedagogical technologies and information technology.

To solve such problems it is required to modernize the content of existing curricula and programs in the field of technology education, the use of effective forms and methods of teaching in the educational process, enhancing students' teaching and methodological skills, and improving their professional and pedagogical skills as well. On the basis of this, there is a need to improve the level of professional training of future technology teachers, to develop a modern methodological basis for up-to-date teaching based on advanced pedagogical technologies. This, in turn, involves the preparation of a future technology teacher based on new pedagogical technologies, primarily justifying the essence of pedagogical technology, identifying the characteristics of the technological approach, the main characteristics (structures and functions), and the factors influencing them [2].

Implementation of this innovative approach requires the formation of learning objectives and methods, the identification of the elements and relationships that ensure the proper functioning of the learning process.

\section{Literature Review}

New concepts such as "Pedagogical technology", "Progressive pedagogical technology", "New information technology" and "Modern pedagogical technologies" are used in the literature devoted to pedagogy in the last decades. However, they have not been fully described in details. The concept of "Pedagogical technology" appeared in the twentieth century (1940-1950) and was used as "Educational technology", which meant the use of audiovisual techniques in the educational process. The term was first used in the United States. Later, instead of
"Educational Technology", "Programmed Learning Technology" was begun to express the learning and goal-oriented learning process. In the $80 \mathrm{~s}$ of the last century, pedagogical technology began to be used synonymously with computer and information technology. One of the issues that has attracted the attention of pedagogical scientists and teachers in recent decades is "Pedagogical technology".

First of all, the question comes as why the interest in pedagogical technology is so growing today. It can be said that in developing countries, pedagogical technology has generally been seen primarily as a major task of education policy. This approach was also endorsed by UNESCO, and in 1972 the International Commission on the Development of Education was established. The commission assessed that modern technology is a driving force in the modernization of education.

First, let's clarify the concept of "technology". The word entered science in 1872. Derived from the Greek, "technos" means art, skill, craft; "logos" means science.

By foreign researchers N.V. Kuzmina, Yu.K.Babansky, V.P. Bespalko and others were conducted investigations on the concept and essence of pedagogical technology, effective tools for training and developing technical thinking, independent research, also regular knowledge and skills for launching them in practice.

Russian scientist V.P.Bespalko was one of the first to scientifically substantiate the need to introduce pedagogical technology into the educational process. According to Bespalko opinion, "Pedagogical technology is a project of the process of forming a student's personality that can guarantee pedagogical success regardless of the teacher's skills" [3].

V.M. Monakhov, a Russian scientist, drew attention to the definition of pedagogical technology as a system of orderly actions that lead to pre-planned results and must be performed. "He does," he said.

According to the I.Y. Lerner opinion, "Pedagogical technology" defines a goal that can be reliably understood and identified through the learning outcomes reflected in the learners' movement.

Polish scientist J. Bruner acknowledged that "Teaching Technology is a field of knowledge related to a specific system of guidance that ensures the acceptability of teaching".

The Russian scientist Talizina explained the essence as "the determination of rational ways to achieve a set learning goal" [4].

The analysis of the research problem shows that the pedagogical bases of teaching and methodical support of the future teacher of labor and vocational training have been developed by the pedagogical scientists of the Republic Uzbekistan A.R. Hodjabaev on the problems of improving the training of teachers of vocational training. 
Scientist N.A. Muslimov studied the scientific and methodological bases of formation of professional pedagogical qualities of the future teacher of professional education. Also he studied to bring up a new generation of specialists spiritually matured, having independent worldview and creative thinking, adhering universal and national values.

Professor N.N.Azizhodzhaeva researched the problems of application of pedagogical technologies in the educational process and improvement of pedagogical skills.

U.K. Tolipov conducted research on "Pedagogical technologies for the development of general labor and professional skills in the system of higher education". He explored the role of pedagogical technologies in the development of professional skills of future teachers and their launch in the educational process.

From the above, it is clear that the main task of the scientific research work is to improve the professional skills of future professional teachers and to use their experience in the use of modern information technologies and their introduction into the educational process.

\section{Analysis}

The analysis of the above research suggests that "Pedagogical technology" comes from the purpose and content of primary education.

This is true in one sense, but if one thinks more deeply, one-sidedness of it is obvious or the denial of the reader's personality is felt in such an approach. This shortcoming was first addressed by V.P. Bespalko noticed and described in his work "Pedagogical technology is the expression-design of the process of formation of the student's personality, which can guarantee pedagogical success". Analyzing the above ideas, we can say that "Pedagogical technologies", "Modern educational technologies" are the content of the educational process, which reveals the essence of the educational system, provides optimization and improvement of educational processes. The main content of our research work is also focused on this. On this basis, we took our research work on the example of the educational process in the field of technical education in higher education and conducted experimental classes. In the process of experimental lessons, using "Pedagogical technologies", "Modern educational technologies", we determined the level of formation of knowledge, skills and abilities of students.

So, in order to achieve these goals, it is necessary to technologicalize the teaching process, to know in advance the ways to achieve the intended goal, to improve the professional activity of future young professionals. Based on the experiments, we had the following ideas. "Pedagogical technology" is a systematic method of defining the process of teaching and learning, creating and applying the forms of education, optimization tasks and taking into account the capabilities of the individual and their interdependence.

Educational technology is the general content of the learning process, which involves the gradual implementation of a pre-designed learning process through a holistic system, the development of specific systems, methods and tools to achieve a specific goal and their efficient use and high-level management of the learning process [5,6].

Comparative analysis of the above-mentioned scientists' research, we have conducted pilot experiments on the example of "technology services" in the field of technology of higher education institution.

Today, the rapid introduction of information technology from modern educational technologies, computerization of the educational process has become one of the most actual problems. The importance of the computer in the field of education, which is one of the didactic tools, is incomparable. It covers issues ranging from the administrative management of the higher education system to the organization, management, control of individual school activities, from the organization of the study of academic subjects to the organization of individual lessons of students.

The advantages of computer technology are:

- The time for students to develop certain skills is reduced; the number of assignments to be practiced will increase;

- The pace of student work is accelerating;

- As a result of the need for active computer control, the student becomes a subject of education;

- Students will have the opportunity to model and directly demonstrate processes that are difficult to observe;

- It is possible to provide the lesson with remote resources using the means of communication;

- Communication with the computer takes on the character of a didactic game, thereby increasing the motivation of students to learning activities, and so on $[7,8]$.

One of the optimal aspects of this didactic tool is the creation of an electronic form of all the information using convenient programs, which creates more creative skills for future professionals. That is, if electronic complexes, e-learning developments are developed and put into practice, students will have enough skills from such an opportunity and will be able to work independently, that is, a subject of the educational process. In this research work, using the above-mentioned didactic methods, forms of modern educational technologies, as well as didactic software training tools, we have conducted experimental work in groups on the example of "Service" in the field of technological education. 


\section{Mechanisms (Methodology) for Carrying Out Experimental Works}

The purpose of experimenting and testing: to determine the level of effective use of pedagogical conditions that allow students to use modern pedagogical technologies in the teaching process of technology education; to develop the factors that motivate them to learn independently.

For this purpose the following tasks were solved:

- Identification of information on the importance of the process of organizing students' use of modern pedagogical technologies in the course of service courses of technology education using questionnaires;

- $\quad$ to study the degree of students' ability to use modern pedagogical technologies in the course of service activities directly on the example of technology and using the tasks for independent work.

Students were divided into experimental and control groups to determine the effectiveness of the experimental work. In the experimental group based on the methodology recommended by the researcher to help students to use modern pedagogical technologies, practical work was carried out in the control group.

35 students (18 experiments, 17 control groups) participated in the technology-based learning process during the academic year.

Assessment of students' knowledge was based on a 100-point rating system.

The experimental work was carried out in accordance with the state educational standards and educational objectives.

In the control group, the learning process was conducted in the "control" group in a traditional way. In this form of lecture, the teacher conducted a lecture and students only listened. Students remembered what they had heard and answered some questions.

In the "Experiment" group the teaching process was conducted in an unconventional way, designed on the basis of pedagogical technologies. In this case the teacher designs the subject in advance. Purposeful use of lessons is based on learning technologies. In this form, the student center is centered on the learning process.

During the experiment, trainings were organized based on a number of technologies and methods, such as "Person-centered learning technologies" - "FSMU technology", "Case study", "Working in small groups", "B/B/B". Demonstrative methods were used to explain the topics of practical training in the field of technological education, problem situations were created, discussions were organized and students' opinions were shared. The purpose of this approach is to increase creative activity in students, the formation of independent thinking and the development of creativity [9-15]. Selection of the target content for the course, demonstration of the proper delivery of teaching materials to the students, analysis, and follow-up of instructions on how students can apply the knowledge gained during practice.

\section{Discussion}

\section{Description of the technologies used in the course}

\section{FSMU Technology}

FSMU technology can be used to resolve contentious issues, debates, or curricula after a section has been studied, as this technology allows listeners to defend their opinions, think freely and communicate their ideas to others, debate openly, as well as educate students. Also it teaches students to analyze the knowledge they have acquired in the learning process, to assess how well they have mastered it, and to engage the audience in a culture of debate.

This technology helps the listener to express their opinions clearly, concisely, and to state affirmative arguments or denials.

In the class, each student first completes an assigned task individually, then works in small groups and works as a team at the end of the lesson.

Leaflets with the 4th stage of FSMU technology will be distributed to each listener: FSMU technology can be used to resolve contentious issues, debates, or curricula after a section has been studied, as this technology allows listeners to defend their opinions, think freely and communicate their ideas to others, debate openly, as well as educate students, teaches students to analyze the knowledge they have acquired in the learning process, to assess how well they have mastered it, and to engage the audience in a culture of debate.

This technology helps the listener to express their opinions clearly, concisely, and to state affirmative arguments or denials.

In the class, each student first completes an assigned task individually, then works in small groups and works as a team at the end of the lesson.

Leaflets with the 4th stage of FSMU technology will be distributed to each listener:

F- express your opinion

S- show the reason of your expressions.

$\mathrm{M}$ - prove the reason giving some examples.

U- conclude your opinion. 
Listeners complete the task individually. The small groups are then formed, and in the small group, each learner reads and introduces their written answer, and then the group members discuss it together, write the general answer, and defend it.

The direction of technological education. Let's look at an example of the subject of service science.

Theme: Drawing the basic sketch of a girl's shirt from Uzbek national costumes. Dress modeling.

Students were explained the content of the technology, questionnaires were distributed, and a time limit was set. Students took an independent, personal approach to the questions on the topic and expressed their views in the table. Investigators conducted an investigation.

Table 1. Complete problematic table

\begin{tabular}{|c|c|l|}
\hline $\mathrm{F}$ & Express your opinion about given problem. & \\
\hline $\mathrm{S}$ & Indicate the causes of the problem. & \\
\hline $\mathrm{M}$ & Give reasons for the problems your cite. & \\
\hline $\mathrm{U}$ & Conclude opinions mentioned above & \\
\hline
\end{tabular}

Table 2. Example of filling in the problem table

\begin{tabular}{|c|l|l|}
\hline F & $\begin{array}{l}\text { Express your opinion } \\
\text { about given problem. }\end{array}$ & $\begin{array}{l}\text { I want our nationality to be } \\
\text { harmonized. }\end{array}$ \\
\hline S & $\begin{array}{l}\text { Indicate the causes of } \\
\text { the problem. }\end{array}$ & $\begin{array}{l}\text { The types of clothes that are not } \\
\text { typical of our mentality are } \\
\text { growing. }\end{array}$ \\
\hline $\mathrm{M}$ & $\begin{array}{l}\text { Give reasons for the } \\
\text { problems your cite. }\end{array}$ & $\begin{array}{l}\text { Because our national costumes, } \\
\text { which show the superiority of } \\
\text { our culture and spirituality are } \\
\text { becoming less and less. }\end{array}$ \\
\hline $\mathrm{U}$ & $\begin{array}{l}\text { Conclude opinions } \\
\text { mentioned above }\end{array}$ & $\begin{array}{l}\text { That is why I want our national } \\
\text { costumes to be revived and our } \\
\text { traditions to be richer. }\end{array}$ \\
\hline
\end{tabular}

\section{Method of Case study}

"Case study" in an English word, ("case" - definite condition, event, "study" - acquire, analyze) the study of specific situations is a method aimed at implementing teaching based on analysis [8].
Table 3. Stages of implementation of the "Case Study" method in the experimental group

\begin{tabular}{|l|l|}
\hline \multicolumn{1}{|c|}{ Stages of work } & Form and content of activities \\
\hline $\begin{array}{l}\text { Step 1: Introduce } \\
\text { Case and his } \\
\text { information support }\end{array}$ & $\begin{array}{l}\text { individual audio-visual work; } \\
\text { acquaintance with the case (in text, audio } \\
\text { or media form); } \\
\text { Generalization of information; } \\
\text { Analyses of information; } \\
\text { Defining problems. }\end{array}$ \\
\hline $\begin{array}{l}\text { Step 2: Identify the } \\
\text { case and assign and and } \\
\text { study assignment }\end{array}$ & $\begin{array}{l}\text { work individually and with groups; } \\
\text { defining actual hierarchy of problems; } \\
\text { identify the main problem situation. }\end{array}$ \\
\hline $\begin{array}{l}\text { Step 3: Search for a } \\
\text { solution to the } \\
\text { learning task by } \\
\text { analyzing the main } \\
\text { problem in the case, } \\
\text { developing solutions }\end{array}$ & $\begin{array}{l}\text { work individually and with groups; } \\
\text { issuing alternative solutions; } \\
\text { each solution; } \\
\text { Choosing alternative solutions }\end{array}$ \\
\hline $\begin{array}{l}\text { Step 4: Case solution } \\
\text { formulation and } \\
\text { justification, } \\
\text { presentation. }\end{array}$ & $\begin{array}{l}\text { कork individually and with groups; } \\
\text { substantiate the possibility of practical } \\
\text { application of alternatives; } \\
\text { preparation of creative-project } \\
\text { presentation; ижодий-лойиха } \\
\text { такдимотини тайёрлаш; } \\
\text { highlighting the final conclusion and } \\
\text { practical aspects of the situation solution. }\end{array}$ \\
\hline
\end{tabular}

The training was based on the above technologies, a number of active methods, as well as computer-based teaching methods. At the end of the training, the activities of the groups were studied and the results were analyzed.

\section{The initial state of students in experimental classes}

It was calculated that the students in the group met the state educational standards. To determine the effectiveness of teaching technology on the basis of the new pedagogical technologies, the students' final questions, the results of tests and generalization sessions were analyzed in terms of quality and quantity.

The analysis of experimental works used the methods of scientific research in pedagogy using mathematical and statistical methods.

The following table 4 shows the dynamics (in both numbers and \%) of students' knowledge dynamics in the process of teaching based on new pedagogical technologies.

Table 4. The dynamics (in both numbers and \%) of students' knowledge dynamics in the process of teaching based on new pedagogical technologies

\begin{tabular}{|c|c|c|c|c|c|c|}
\hline \multirow{2}{*}{$\begin{array}{l}\text { Experience level } \\
\text { and phase }\end{array}$} & \multirow{2}{*}{$\begin{array}{l}\text { Higher } \\
\text { Institution }\end{array}$} & \multirow{2}{*}{$\begin{array}{l}\text { Acquiring } \\
\text { degree }\end{array}$} & \multicolumn{2}{|c|}{ In the beginning of the experience } & \multicolumn{2}{|c|}{$\begin{array}{c}\text { In the end } \\
\text { of the experience }\end{array}$} \\
\hline & & & In experimental group & $\begin{array}{l}\text { In control } \\
\text { group }\end{array}$ & In experimental group & $\begin{array}{l}\text { In control } \\
\text { group }\end{array}$ \\
\hline \multirow{3}{*}{$\begin{array}{c}2020 \text { Academic } \\
\text { year }\end{array}$} & \multirow{3}{*}{$\begin{array}{c}\text { Bukhara State } \\
\text { University }\end{array}$} & $\begin{array}{l}\text { The highest } \\
\text { (excellent) }\end{array}$ & 6 & 4 & 14 & 6 \\
\hline & & high (good) & 13 & 4 & 8 & 10 \\
\hline & & $\begin{array}{c}\text { average } \\
\text { (satisfied) }\end{array}$ & 6 & 15 & 3 & 10 \\
\hline
\end{tabular}


Table 5. Indicators of the formation of skills and abilities of students with the use of pedagogical technologies in the subject "Technology"

\begin{tabular}{|c|c|c|c|c|c|c|}
\hline \multirow{2}{*}{$\begin{array}{l}\text { Experience level } \\
\text { and academic year }\end{array}$} & \multirow{2}{*}{$\begin{array}{l}\text { Educational } \\
\text { Institution }\end{array}$} & \multicolumn{2}{|c|}{ Number of students } & \multirow{2}{*}{$\begin{array}{c}\text { Level } \\
\text { (acquiring) } \\
\end{array}$} & \multirow{2}{*}{$\begin{array}{l}\text { In Experimental } \\
\text { group } \\
\end{array}$} & \multirow[t]{2}{*}{ In control group } \\
\hline & & $\begin{array}{l}\text { In experimental } \\
\text { group }\end{array}$ & $\begin{array}{l}\text { In control } \\
\text { group }\end{array}$ & & & \\
\hline \multirow{3}{*}{$\begin{array}{c}2020 \text { Academic } \\
\text { year }\end{array}$} & \multirow{3}{*}{$\begin{array}{l}\text { BSU Higher } \\
\text { educational } \\
\text { institution }\end{array}$} & \multirow{3}{*}{25} & \multirow{3}{*}{26} & $\begin{array}{l}\text { The highest } \\
\text { (excellent) }\end{array}$ & 14 & 6 \\
\hline & & & & $\begin{array}{l}\text { High } \\
\text { (good) }\end{array}$ & 8 & 10 \\
\hline & & & & $\begin{array}{l}\text { Average } \\
\text { (satisfied) }\end{array}$ & 3 & 10 \\
\hline
\end{tabular}

Indicators of the formation of skills and abilities of students in the field of "Technological Education" using modern pedagogical technologies in the classroom are expressed on the basis of Table 5 .

Based on this information, we will introduce the following:

$x_{i}$ then we set the ratings appropriate for the experimental group;

$y_{i}$ we set the scores for the control group;

$\bar{x}$ and $\bar{y}$ quantities are the mean arithmetic mean values for the experimental and control groups.

Then

$$
\bar{x}=\frac{\sum x_{i} n_{i}}{n}, \bar{y}=\frac{\sum y_{i} m_{i}}{m}
$$

Equations will be appropriate.

$n$ the equations, the variables $x_{i}, y_{i}$ accept the values of $3,4,5$, respectively.

$m$ and $n$ are the number of students relative to the corresponding grades.

It is noteworthy that the average value for evaluating the effectiveness of the learning process is the ratio of the arithmetic mean scores of the experimental and control groups, that is, coefficients of effectiveness.

$$
\eta=\frac{\bar{x}}{\bar{y}}
$$

Medium squared deviation:

$S_{x}^{2}=\frac{1}{n} \sum_{i} n_{i} \cdot\left(x_{i}-\bar{x}\right)^{2}, \quad S_{y}^{2}=\frac{1}{m} \sum_{i} m_{i} \cdot\left(y_{i}-\bar{y}\right)^{2}$

Standard deviation sizes:

$$
S_{x}=\sqrt{S_{x}^{2}}, \quad S_{y}=\sqrt{S_{y}^{2}}
$$

Average value indication

$$
\tilde{N}_{x}=\frac{S_{x}}{\sqrt{n} \cdot \bar{x}} \cdot 100 \% ; \quad \tilde{N}_{y}=\frac{S_{y}}{\sqrt{m} \cdot \bar{y}} \cdot 100 \%
$$

Confidence intervals for the mean values of an empty set:

$$
\begin{aligned}
& a_{x} \in\left[\bar{x}-\frac{t}{\sqrt{n}} \cdot S_{x} ; \bar{x}+\frac{t}{\sqrt{n}} \cdot S_{x}\right], \\
& a_{y} \in\left[\bar{y}-\frac{t}{\sqrt{m}} \cdot S_{y} ; \bar{y}+\frac{t}{\sqrt{m}} \cdot S_{y}\right]
\end{aligned}
$$

Here $t$ normalization is determined by the $R$ probability of reliability.

For example: $R=0,95$ is equal to $t=1,96$.

We contradict the assumption $H_{0}: a_{x}=a_{y}$ that the mean values are equal, then we opposite $H_{1}: a_{x} \neq a_{y}$ based on the information above, we will check by student criteria.

$$
T=\frac{|\bar{y}-\bar{x}|}{\sqrt{\frac{S_{x}^{2}}{n}+\frac{S_{y}^{2}}{m}}}
$$

If $T>T_{r}=t, H_{0}$ the hypothesis is rejected, $H_{1}$ hypothesis is accepted.

Below are the tables and calculations for each phase based on these data.

The following research investigated the initial results of students' experimental works and also their level of autonomous learning, knowledge, skills and qualification in the field of Service through oral and written assessment at the end of experiment.

\section{Comparative analysis of the experimental work:}

$m=25, n=26$ number of students in experimental and control groups.

$a$ - at the beginning of the experiment.

$O \quad$ - at the end of the experience.

$$
\overline{x_{a}}=3,6, \overline{y_{a}}=3,58 .
$$

Efficiency coefficient:

$$
\eta_{a}=\frac{\bar{x}_{a}}{\bar{y}_{a}}=\frac{3,6}{3,58}=1,01
$$


The following equations are obtained for standard deviation values:

$$
\begin{gathered}
S_{x_{a}}^{2}=0,64 ; S_{x_{a}}=\sqrt{S_{x_{a}}^{2}}=0,8 \\
S_{y_{a}}^{2}=0,55 ; \quad S_{y_{a}}=\sqrt{S_{y_{a}}^{2}}=0,74 .
\end{gathered}
$$

Average values clearifying indicators:

$$
\begin{gathered}
\tilde{N}_{x_{a}}=4,44 \% ; \quad \tilde{N}_{y_{a}}=4,05 \% ; \\
a_{x_{a}} \in[3,29 ; 3,91] ; \quad a_{y_{a}} \in[3,3 ; 3,86]
\end{gathered}
$$

We will calculate these results at the end of the experiment:

$$
\overline{x_{o}}=4,44 ; \quad \overline{y_{o}}=3,85
$$

$\eta_{o}=\frac{\bar{x}_{o}}{\bar{y}_{o}}=\frac{4,44}{3,85}=1,15$ - relative growth.

Thus, the experimental group was 1,15 times higher than the control group at the end of the experiment.

If we compare it to the beginning of the experiment:

In experimental group

$$
\eta_{1}=\frac{\bar{x}_{o}}{\bar{x}_{a}}=\frac{4,44}{3,6}=1,23
$$

In control group

$$
\eta_{2}=\frac{\bar{y}_{o}}{\bar{y}_{a}}=\frac{3,85}{3,58}=1,08
$$

Efficiency has been gained.

The standard deviation for the magnitude of the following modules

$$
\begin{gathered}
S_{x_{o}}^{2}=0,49 ; S_{x_{o}}=0,7 ; \\
S_{y_{o}}^{2}=0,59 ; S_{y_{o}}=0,77 .
\end{gathered}
$$

Medium values defining indicators:

$$
\begin{gathered}
\tilde{N}_{x_{o}}=3,15 \% ; \quad \tilde{N}_{y_{o}}=3,92 \% ; \\
a_{x_{o}} \in[4,17 ; 4,71] ; \quad a_{y_{o}} \in[3,55 ; 4,15]
\end{gathered}
$$

Mathematical and statistical analysis of the results for each stage was conducted, and based on these criteria the Student's criteria were checked and summarized.

In the beginning of the experience:

$$
\bar{x}_{a}=3,6 \text { and } \bar{y}_{a}=3,58
$$

$$
T_{a}=\frac{|\bar{y}-\bar{x}|}{\sqrt{\frac{S_{x_{a}}^{2}}{n}+\frac{S_{y_{a}}^{2}}{m}}}=0,09 ; T_{a}=0,09<T_{0,96}(t)=1,96 .
$$

\begin{tabular}{|c|c|c|c|c|c|c|}
\hline \multirow[b]{2}{*}{ № } & \multirow[b]{2}{*}{ Indicators } & \multirow{2}{*}{$\begin{array}{l}\text { Higher } \\
\text { education }\end{array}$} & \multicolumn{2}{|c|}{ In the beginning of the experience } & \multicolumn{2}{|c|}{ In the end of the experience } \\
\hline & & & $\begin{array}{l}\text { In experimental } \\
\text { group }\end{array}$ & In control group & $\begin{array}{l}\text { In experimental } \\
\text { group }\end{array}$ & In control group \\
\hline 1 & $\begin{array}{l}\text { Medium arithmetic value } \\
(\bar{x}, \bar{y})\end{array}$ & BSU & 3,6 & 3,58 & 4,44 & 3,85 \\
\hline 2 & Efficiency indicator $(\boldsymbol{\eta})$ & BSU & \multicolumn{2}{|c|}{1,01} & \multicolumn{2}{|c|}{1,15} \\
\hline 3 & $\begin{array}{l}\text { Medium value confidence } \\
\left.\text { distance ( } a_{x} \in, a_{y} \in\right)\end{array}$ & BSU & {$[3,29 ; 3,91]$} & {$[3,03 ; 3,86]$} & {$[4,17 ; 4,71]$} & {$[3,55 ; 4,15]$} \\
\hline 4 & $\begin{array}{l}\text { Medium value standard } \\
\text { error }\left(S_{x}, S_{y}\right)\end{array}$ & $\mathrm{BSU}$ & 0,8 & 0,74 & 0,7 & 0,77 \\
\hline 5 & $\begin{array}{l}\text { Defining indicator } \\
\left(S_{x}, S_{y}\right)\end{array}$ & $\mathrm{BSU}$ & $4,44 \%$ & $4,05 \%$ & $3,15 \%$ & $3,52 \%$ \\
\hline 6 & Student $(\mathrm{T})$ criteria & BSU & \multicolumn{2}{|c|}{0,09} & \multicolumn{2}{|c|}{2,95} \\
\hline 7 & Results of indicators & BSU & \multicolumn{2}{|c|}{$\begin{array}{c}\boldsymbol{H}_{\mathrm{O}} \\
\text { hypothesis will be accepted }\end{array}$} & \multicolumn{2}{|c|}{$\begin{array}{c}H_{1} \\
\text { hypothesis will be accepted }\end{array}$} \\
\hline
\end{tabular}

Thus $H_{0}$ hypothesis will be accepted.

In the end of the experience:

$$
\bar{x}_{o}=4,44 \text { and } \bar{y}_{o}=3,85
$$

$$
T_{o}=\frac{|\bar{y}-\bar{x}|}{\sqrt{\frac{S_{x_{o}}^{2}}{n}+\frac{S_{y_{o}}^{2}}{m}}}=2,95 ; T_{o}=2,95>T_{0,96}(t)=1,96 .
$$

Thus $H_{1}$ hypothesis will be accepted.

The initial state of the level of knowledge of students in the field of service and the increase in the effectiveness of the results after the use of modern educational technologies were identified in the analysis and expressed in growth indicators (Table 6).

Table 6. Performance indicators of student knowledge. The degree of formation of students' knowledge and skills in the use of pedagogical technologies in the teaching process 
Consequently, the results from the table show that the methodology used in the experimental group was more effective than the control group.

The results of the experimental tests showed that students' ability to use technology in the teaching process of the educational process was achieved by 1,23 -fold in the experimental group and 1,08-fold in the control group.

The comparative analysis of the indicators of the formation of knowledge, skills and competences of students based on the obtained scientific results in the technological process of the classroom process is presented in the following histograms.

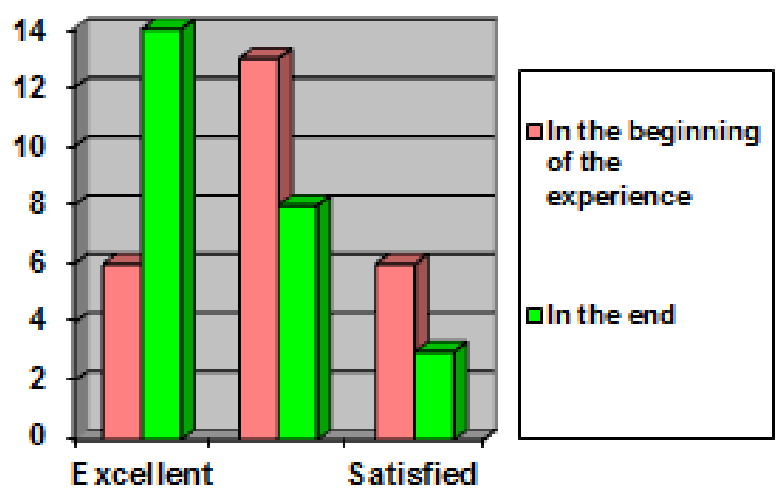

Figure 1. Histogram of experimental group results

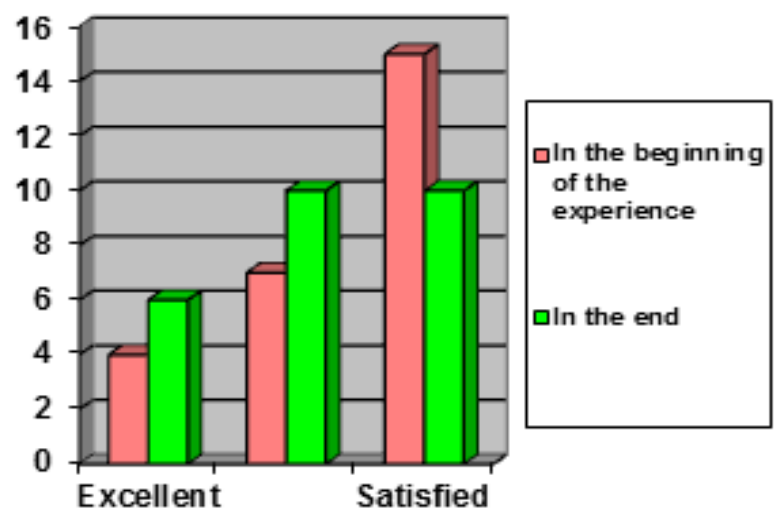

Figure 2. Histogram of control group results.

As can be seen from the histogram, the indicators of formation of skills and abilities of students using modern educational technologies in the field of technological education increased from $31 \%$ to $68 \%$ in the group "Experience" and from 22\% to $30 \%$ in the group "Control". The status of the above experimental work shows that the technology of teaching processes: not only increases the level of knowledge of students, but also guarantees the quality of teaching processes.

\section{Conclusions}

In short, the main purpose of our research is to free the educational process from the system of uniformity, to adapt the higher education process to modern requirements, to improve the education system through the application of foreign experience. The main task of our research is to provide practical, laboratory rooms with modern equipment, to teach future professionals in detail the secrets of the profession through the introduction of modern technologies, to encourage them to be aware of different methods of production, to develop conditions such as adapting a learner to an independent, and creative approach.

In order to achieve such lofty goals and objectives, of course, a thorough knowledge of the content of modern educational technologies is based on foreign experience, through which the optimization, planning and technological design of educational processes. In our research, the use of "Modern educational technologies" has the following advantages:

- Interaction and active participation of teachers and students; because if the teacher becomes the main figure in the lesson, the students 'sense of responsibility and accountability diminishes.

- Independent thinking, observation of students;

- Promotion of new ideas by students;

- Increased interest in science;

- Share each other's thoughts.

In addition, the introduction of "Modern educational technologies" in the educational process allows students to develop initiative and independence from the teacher, the acquisition of knowledge, the necessary skills and abilities, their observation, thinking, logical speech, memory and creative imagination.

The methodology of using modern educational technologies in the educational process of technological education has been improved, and the use of "Person-centered technologies" and "computer-based learning technologies" has been recommended for the formation of creative skills of students in general and specialty subjects.

\section{Acknowledgements}

The authors are indebted to the anonymous referees for a number of constructive comments.

\section{REFERENCES}

[1] Davlatov K., Theory and methods of professional education and vocational education, Tashkent; 1992 y. page 319.

[2] Matchanov S., "Organizing literary work in the general education system". Autoref. dis. ... Ped. - T.: 1998. - 42 p.

[3] Bespalko V.P. Pedagogy and progressive learning technologies.- Moscow, Institute Publishing House vocation Ministry of Education of Russia, 1995. P. 378. 
[4] Babanskiy Y.K. Optimization of the educational process. Methodological foundations. - Moscow: Pedagogy, 2005. P. 193.

[5] Muslimov N.A., "Professional formation of future vocational teachers," Monograph. - Tashkent: Science, 2004. $-128 \mathrm{p}$.

[6] Husanboeva K.P., "Scientific and methodological foundations for teaching students to think independently in the literary education process," Dis. ... PhD. - Tashkent: Uz SPI, 2004. - $261 \mathrm{p}$.

[7] Mukhina S.A., Solovyova A.A. Modern innovative teaching technologies / - Moscow.: "GEOTAR-Media ", 2008.

[8] Zeer E.F., Shakhmatova N. Personally-oriented technologies of professional development of a specialist.-Ekaterinburg, Russia, 1999. P. 244.

[9] Rasulova Z.D., Pedagogical peculiarities of developing socio-perceptive competence in learners. European Journal of Research and Reflection in Educational Sciences. Vol. 8, No. 1, 2020, pp. 30-34.

[10] Rasulova Z.D., Conditions and opportunities of organizing independent creative works of students of the direction
Technology in Higher Education. International Journal of Scientific and Technology Research. Vol. 9, No. 3, 2020, pp. 2552-2155.

[11] Rasulov T.H., Rasulova Z.D., Organizing educational activities based on interactive methods on mathematics subject. Journal of Global Research in Mathematical Archives, 6 (2019), No. 10, pp. 43-45.

[12] Juraev A.R., Methods of applying virtual laboratories in teaching hydraulics and heat technology. European Journal of Research and Reflection in Educational Sciences. 7:6 (2019), pp. 35-40

[13] Rasulova Z.D., Didactic basis of developing creative thinking of future teachers. European science. 2020, vol. 51, no. 2-2, pp. 65-68.

[14] Kakhkhorov S.K., Jamilov Y.Y. Opportunities of the formation of students' competence on alternative energy using training software devices. European science, 2020, vol. 51, no. 2-2, pp. 61-64.

[15] Rasulov T.H., Rashidov A.Sh., The usage of experience in effective organization of teaching activities in foreign Mathematics. International journal of scientific \& technology research. 9 (2020), no. 4, pp. 3068-3071. 